\title{
Digital Signage Berbasis Raspberry Pi 3
}

\author{
Enggartiasto Faudi Ristyawan, Eko Mulyanto, dan Arief Kurniawan \\ Departmen Teknik Komputer, Fakultas Teknologi Elektro, Institut Teknologi Sepuluh Nopember \\ E-mail : enggartiasto13@mhs.te.its.ac.id | ekomulyanto@gmail.com | arifku.tmj@gmail.com
}

\begin{abstract}
Abstrak-Digital Signage adalah teknologi informasi digital yang dikemas dalam memberikan tontonan visual yang menarik dan atraktif, memuat beraneka informasi berupa gambar, video, scroll text, chart, grafik, jadwal, berita, cuaca yang disajikan secara dinamik menggunakan media display elektronik seperti LCD/LED TV, Proyektor maupun digital billboard sebagai output. Penampilan informasi tambahan dan revisi pada suatu informasi digital membuat penampilan informasi kurang cepat dalam perubahan dan membutuhkan proses yang cukup panjang hanya untuk itu. Dengan dikembangkannya perangkat single board computer serta video processing dapat digunakan untuk memberikan informasi melalui digital signage secara real-time dan cepat sehingga tidak perlu melalui proses panjang untuk menampilkan informasinya. Single Board Computer yang digunakan pada alat adalah berupa Raspberry Pi yang berfungsi untuk mengambil informasi dari database yang terdapat hasil informasi yang telah di kirim melalui komputer sebelumnya.
\end{abstract}

Kata kunci-Single Board Computer, Raspberry Pi, Digital Signage, Webserver

\section{PENDAHULUAN}

$\mathrm{D}$ igital Signage merupakan sebuah bentuk penyampaian informasi melalui media display elektronik. Dengan menggunakan teknologi LCD, plasma, atau LED yang semakin hari semakin canggih dan terjangkau, ditambah dengan kemudahan pemakaian, membuat Digital Signage menjadi tren penyampaian informasi di berbagai negara maju. baik digunakan sekedar menyampaikan informasi satu arah (pemberi informasi ke masyarakat) ataupun informasi dua arah (pemberi informasi ke dan dari masyarakat) dengan memanfaatkan teknologi interaktif.[1] Di Eropa/Amerika hampir semua tempat bisnis, area publik, perkantoran, tempat hiburan telah mengganti media komunikasi konvensional mereka menjadi media digital dengan tujuan memudahkan komunikasi antara konsumen dan toko, menaikan image perusahaan, memperkenalkan branded produk agar lebih dikenal luas konsumen. [2]

Terdapat beberapa metode yang digunakan pada Digital signage. Metode pertama adalah produk digital signage yang berupa layar dengan player internal pada hardwarenya. Namun, harga dariperangkat digital signage ini yang beredar di pasaran cenderung lebih mahal. Harga digital signage dengan player internal masih berkisar diatas 9 juta, tergantung dari ukuran displaynya. Digital signage dengan metode lainnya adalah dengan menggunakan perangkat berupa hardware yang dihubungkan dengan layar display.

Raspberry Pi 3, sebagai Single Board Computer yang memiliki banyak kemampuan serta kompatibel dengan memori hingga 32GB dapat digunakan untuk menyelesaikan masalah ini. Dengan Raspberry Pi 3 yang harganya lebih terjangkau, maka akan dapat mengurangi biaya yang tidak seharusnya dikeluarkan oleh pengguna digital signage tersebut.

\section{DESAIN SISTEM}

Digital Signage Menggunakan Raspberry Pi 3 Berbasis Server dibangun pada sebuah SBC (Single Board Computer) berupa Raspberry Pi 3. Raspberry Pi 3 bertugas sebagai media pengolahan citra untuk menampilkan gambar dan video dari input halaman web smartphone /PC. Desain umum sistem dapat dilihat pada Gambar 1.

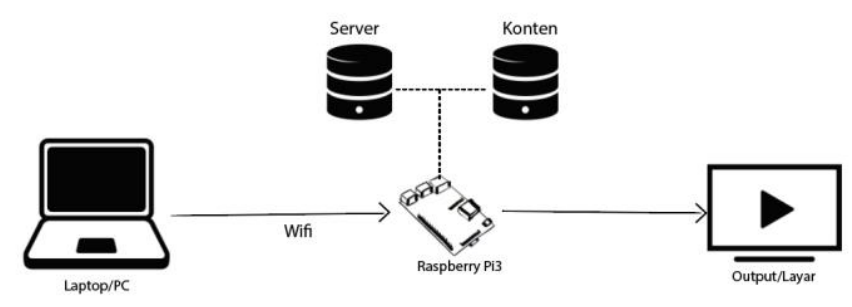

Gambar 1 Desain Umum Sistem

Untuk lebih jelasnya desain sistem yang digunakan pada raspberry pi 3 dibuatlah use case diagram. Berikut desain sistem dengan use case diagram pada gambar 2.

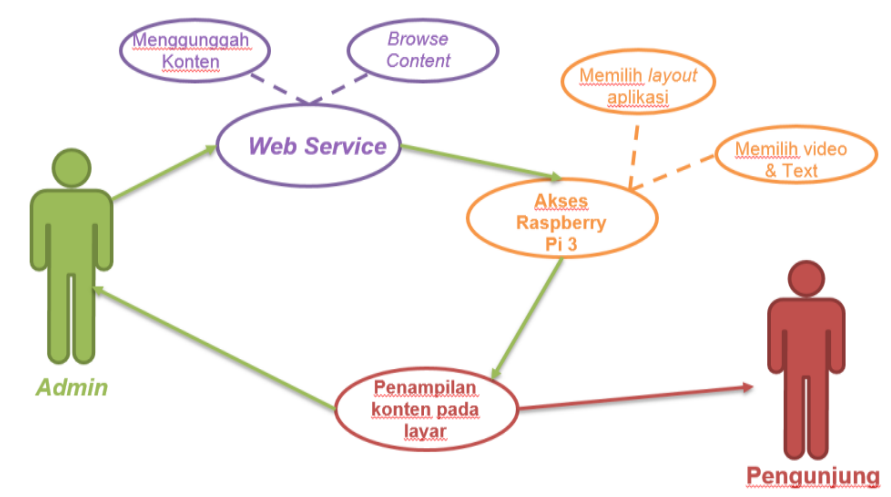

Gambar 2. Use case diagram

Pada gambar 2 Client memiliki 2 fitur yaitu upload content dan browse content. Fitur upload content berfungsi sebagai upload konten menuju raspberry pi 3 untuk dikirimkan ke raspberry pi 3 kemudian ditampilkan ke output konten, dalam hal ini konten berupa video serta gambar. Kemudian fitur Browse Konten berfungsi untuk mengecek konten sudah tersimpan atau belum di raspberry pi 3 .

\section{ALUR KERIA}

Proses alur kerja ini dijelaskan dalam beberapa diagram alir. Diagram alir pertama pada gambar 3, menjelaskan cara kerja sistem dari input menuju server. Diagram alir kedua pada gambar 4 menjelaskan tentang cara pengambilan gambar serta video dari localhost menuju layar penampil digital signage. 


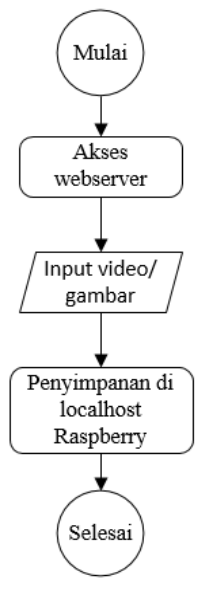

Gambar 3. Diagram alir dari input menuju local raspberry pi 3

Pada gambar 3 diagram alir menjelaskan cara kerja sistem dari input menuju server. Dimana client mengakses server melalui localhost satu jaringan yang sama. Client dapat memilih menu yang ada pada localhost serta dapat mengupload konten agar server dapat mengirimkan ke raspberry. Setelah konten akan tersimpan di localhost raspberry pi.

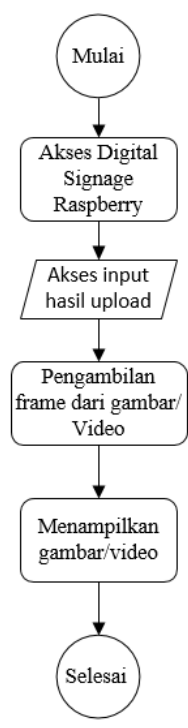

Gambar 4. Diagram alir dari web service menuju Digital Signage

Pada gambar 4 Diagram alir menjelaskan cara kerja sistem dari halaman web menuju Digital signage. Setelah pengiriman konten ke localhost raspberry pi maka konten tersebut akan tersimpan di folder localhost yang akan diakses Digital signage. Konten gambar/video akan diambil dari folder localhost dan ditampilkan melalui digital signage dengan layar yang telah tersedia. Aplikasi digital signage yang digunakan untuk menampilkan konten gambar/video dijalankan menggunakan Raspberry Pi 3. Terdapat layout user interface yang akan dilihat oleh client saat menampilkan konten video/gambar yang dapat dilihat pada gambar 5

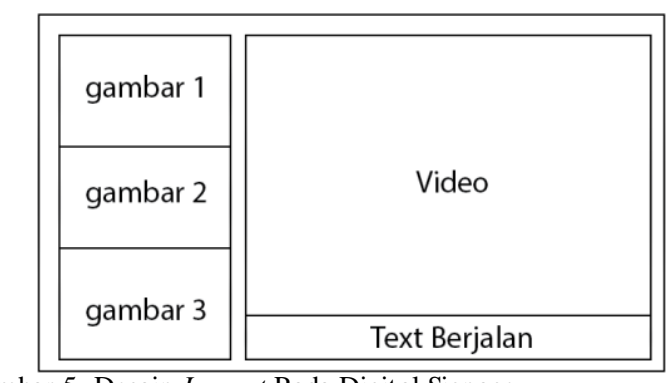

Gambar 5. Desain Layout Pada Digital Signage

\section{PENGUJIAN}

Pengujian pada penelitian ini dilakukan dalam beberapa bagian, yakni pengujian terhadap kemampuan Raspberry Pi 3 Model B+ dalam menjalankan aplikasi Digital Signage serta menampilkan konten berupa gambar/video dan juga menjadi server website. Pengujian dilakukan pada Raspberry Pi 3 Menggunakan sistem operasi Raspbian Jessie Linux. Tabel 1.

Spesifikasi Raspberry Pi 3 Model B+

\begin{tabular}{l|l}
\hline \hline Komponen & Spesifikasi \\
Sistem Operasi & $\begin{array}{l}\text { Raspbian Jessie Linux } \\
\text { Dual Core Video Core IV® } \\
\text { Multimedia Co-Processor } \\
\text { GPU }\end{array}$ \\
Memory & $\begin{array}{l}\text { HDMI Composite RCA (PAL \& } \\
\text { NT SC) }\end{array}$ \\
Video Ouput & $\begin{array}{l}\text { SD Card 16GB } \\
\text { Broadcom BCM2835 SoC Full HD } \\
\text { Multimedia applications processor }\end{array}$ \\
\hline
\end{tabular}

\section{A. Pengujian Performa Menjalankan Video}

Pengujian ini dilakukan untuk mengetahui performa dari perangkat lunak yang telah direalisasikan dalam melakukan proses pemutaran video. Kemampuan perfoma pemutaran video pada Digital Signage ini diuji dengan melihat jumlah frame/detik pada setiap pemutaran video.

Pada pengujian pemutaran video dengan kualitas video yang berbeda dilakukan pengujian dengan menggunakan layar resolusi berukukuran 1600x900 dengan kualitas video yang berbeda-beda.

Pengujian pertama menggunakan dua buah video yang berbeda beserta ketiga kualitas resolusi video yang berbeda juga dengan menggunakan suara. Pada pengujian ini akan dilakukan perhitungan Frame/Detik disetiap proses menjalankan video. Berikut dibawah adalah tabel kualitas video:

Tabel 2.

Hasil Frame/Detik Kualitas Video Menggunakan Suara

\begin{tabular}{llll}
\hline \hline no & Resolusi & Warna & Frame/Detik \\
\hline 1 & $320 \times 240$ & Full- colour & $23 \mathrm{Fps}$ \\
2 & $640 \times 480$ & Full- colour & $20 \mathrm{Fps}$ \\
3 & $1280 \times 720$ & Full- colour & $18 \mathrm{Fps}$ \\
4 & $320 \times 240$ & Black White & $23 \mathrm{Fps}$ \\
5 & $640 \times 480$ & Black White & $23 \mathrm{Fps}$ \\
6 & $1280 \times 720$ & Black White & $20 \mathrm{Fps}$ \\
\hline \hline
\end{tabular}

Tabel 3.

Hasil Frame/Detik Kualitas Video Tanpa Suara 


\begin{tabular}{llll}
\hline \hline no & Resolusi & Warna & Frame/Detik \\
\hline 1 & $320 \times 240$ & Full- colour & $29 \mathrm{Fps}$ \\
2 & $640 \times 480$ & Full- colour & $26 \mathrm{Fps}$ \\
3 & $1280 \times 720$ & Full- colour & $22 \mathrm{Fps}$ \\
4 & $320 \times 240$ & Black White & $29 \mathrm{Fps}$ \\
5 & $640 \times 480$ & Black White & $25 \mathrm{Fps}$ \\
6 & $1280 \times 720$ & Black White & $23 \mathrm{Fps}$ \\
\hline \hline
\end{tabular}

Dari hasil kedua pengujian terdapat hasil performa berupa Frame/Detik tergantung pada resolusi dan kualitas yang diputar. Pengaruh menjalankan suara pada pemprosesan pemutaran video juga membuat frame/detik jadi menurun dibandingkan tidak menggunakan suara.

\section{B. Pengujian Performa Raspberry Pi 3}

Pengujian ini dilakukan untuk mengetahui performa dari raspberry pi 3 yang telah direalisasikan dalam melakukan proses pemutaran video. Kemampuan perfoma pemutaran video pada Digital Signage ini diuji dengan melihat jumlah durasi menyala raspberry pi 3 pada setiap pemutaran aplikasi. Pada pengujian tahap ini, perangkat dijalankan pada layar televisi dengan resolusi yang berbeda-beda dengan memutarkan kualitas video yang sama.

Pada pengujian pemutaran aplikasi ini, terdapat layar dengan ukuran resolusi yang berbeda-beda, yaitu:

Tabel 4.

Merk Layar yang diujikan beserta resolusi pada pengujian kemampuan pemutaran video

\begin{tabular}{lll}
\hline \hline No. & Merk Layar & Resolusi \\
\hline 1 & LG 20M38H 19Inch LED & $1600 \times 900$ \\
2 & LG 32LC4R 32inch LCD & $1366 \times 768$ \\
\hline \hline
\end{tabular}

Tabel 5.

Durasi Performa RaspberryPi3 dalam menjalankan aplikasi

\begin{tabular}{lcl}
\hline \hline No. & Resolusi & Durasi \\
\hline 1 & $1600 \times 900$ & 64 jam 12 menit \\
2 & $1366 \times 768$ & 65 jam 15 menit \\
\hline \hline
\end{tabular}

\section{Pengujian Waktu Eksekusi Unggah Data}

Waktu eksekusi merupakan lama waktu yang terpakai selama berlangsungnya perintah yang tereksekusi. Pada bagian ini pengujian waktu eksekusi pada proses sistemyang melibatkan request kepada webserver. Pengujian dilakukan dengan menggunakan tiga jenis jaringan yaitu:

\section{Kabel LAN}

2. Wi-Fi (Wireless Fidelity)

Hal ini dilakukan untuk mengetahui lama waktu proses transfer data web administrator dalam menggunggah jika menggunakan jaringan dengan media yang berbeda. Pada setiap pengujian dilakukan sepuluh kali percobaan untuk memastikan data yang didapatkan valid dengan mengirimkan file yang sama sebesar 35MB.

Tabel 6.

Hasil kecepatan waktu unggah pada web service.

\begin{tabular}{ccc}
\hline \hline \multirow{2}{*}{ Percobaan } & \multicolumn{2}{c}{ Waktu Eksekusi (Detik) } \\
\cline { 2 - 3 } & LAN & Wi-Fi \\
\hline 1 & 10,33 & 24,71 \\
2 & 11,12 & 34,44 \\
3 & 9,87 & 28,76 \\
5 & 10,45 & 30,22 \\
6 & 10,12 & 29,90 \\
\hline \hline
\end{tabular}

\begin{tabular}{ccc}
\hline \hline 7 & 9,99 & 23,78 \\
8 & 11,21 & 26,79 \\
9 & 10,12 & 27,44 \\
10 & 10,21 & 31,53 \\
\hline \hline
\end{tabular}

Pada tabel 6 ditunjukkan hasil pengujian waktu eksekusi penggunggahan data dengan menggunakan file yang sama. Terlihat perbedaan hasil antar jenis jaringan. Pada jaringan menggunakan media kabel LAN, hasil pengujian menunjukkan hasil rata-rata waktu eksekusi adalah 11,36 detik. Sedangkan pada jaringan Wi-Fi hasil rata-rata waktu eksekusi yang didapat adalah 28,84 detik. Pada jaringan Wifi didapatkan hasil nilai yang cukup besar dibandingkan dengan jaringan yang lain karena. Hal ini disebabkan karena pada Wi-fi terdapat interferensi yang meningkat yang dapat menyebabkan latensi yang lebih tinggi sehingga membuat pengiriman data lebih terhambat atau lebih lama disbanding dua jaringan yang lain.

\section{Pengujian Waktu Eksekusi Unggah Data}

Tabel 7.

Daftar kuisioner pengujian kepuasaan

\begin{tabular}{|c|c|}
\hline No & Pertanyaan \\
\hline 1 & $\begin{array}{l}\text { Apakah warna background dan tulisan yang } \\
\text { ditampilkan sudah sesuai }\end{array}$ \\
\hline 2 & Apakah ukuran gambar sudah sesuai \\
\hline 3 & Apakah ukuran tulisan sudah sesuai. \\
\hline 4 & $\begin{array}{l}\text { Apakah tampilan desain admin Digital Signage } \\
\text { sudah sesuai }\end{array}$ \\
\hline 5 & Apakah aplikasi Digital Signage mudah digunakan \\
\hline 6 & $\begin{array}{l}\text { Apakah aplikasi layar yang digunakan pada } \\
\text { Raspberry Pi } 3 \text { mudah digunakan }\end{array}$ \\
\hline 7 & $\begin{array}{l}\text { Apakah aplikasi layar yang digunakan pada } \\
\text { Raspberry Pi } 3 \text { mudah digunakan }\end{array}$ \\
\hline 8 & $\begin{array}{l}\text { Apakah data gambar dan video yang ditampilkan } \\
\text { sudah jelas dan informatif. }\end{array}$ \\
\hline 9 & $\begin{array}{l}\text { Apakah tampilan UI di layar mempermudah admin } \\
\text { dalam menggunakan aplikasi. }\end{array}$ \\
\hline 10 & $\begin{array}{l}\text { Apakah aplikasi yang telah dibuat membantu dalam } \\
\text { menampilkan informasi gambar dan video }\end{array}$ \\
\hline
\end{tabular}

Kuisioner terdiri atas 10 pertanyaan yang sudah disususn berdasarkan faktor-faktor yang menunjukkan atribut kualitas produk dilihat dari sudut pandang pengguna, dengan pilihan opsi jawaban, yaitu:

1. Sangat Tidak Setuju (STS)

2. Tidak Setuju (TS)

3. Kurang Setuju (KS)

4. Setuju (S)

5. Sangat Setuju (SS).

Tabel 8

Presentase hasil kuisioner pengujian aplikasi Digital Signage.

\begin{tabular}{ccccccc}
\hline \hline \multirow{2}{*}{ no } & \multirow{2}{*}{ Pertanyaan } & \multicolumn{6}{c}{ Jawaban (Dalam \%) } \\
\cline { 3 - 7 } & & STS & TS & KS & S & SS \\
\hline 1 & Pertanyaan 1 & $0 \%$ & $0 \%$ & $0 \%$ & $75 \%$ & $25 \%$ \\
2 & Pertanyaan 2 & $0 \%$ & $0 \%$ & $0 \%$ & $80 \%$ & $20 \%$ \\
3 & Pertanyaan 3 & $0 \%$ & $0 \%$ & $0 \%$ & $80 \%$ & $20 \%$ \\
4 & Pertanyaan 4 & $0 \%$ & $0 \%$ & $0 \%$ & $70 \%$ & $30 \%$ \\
\hline & & \multicolumn{7}{c}{ Konten } & & & \\
\hline 5 & Pertanyaan 5 & $0 \%$ & $0 \%$ & $5 \%$ & $65 \%$ & $30 \%$ \\
\hline \hline
\end{tabular}




\begin{tabular}{lllllll}
\hline \hline 6 & Pertany aan 6 & $0 \%$ & $0 \%$ & $0 \%$ & $65 \%$ & $35 \%$ \\
7 & Pertany aan 7 & $0 \%$ & $0 \%$ & $0 \%$ & $70 \%$ & $30 \%$ \\
\hline \multicolumn{7}{c}{ Usability } \\
\hline 8 & Pertany aan 8 & $0 \%$ & $0 \%$ & $10 \%$ & $60 \%$ & $30 \%$ \\
9 & Pertany aan 9 & $0 \%$ & $0 \%$ & $5 \%$ & $70 \%$ & $25 \%$ \\
10 & Pertany aan 10 & $0 \%$ & $0 \%$ & $0 \%$ & $65 \%$ & $35 \%$ \\
\hline \hline
\end{tabular}

Pengujian dilakukan kepada 20 pengguna yang terbagi kedalam 3 tipe pengguna (15 Pedagang, 5 Mahasiswa). Dari hasil pengujian kuesioner tersebut, dilakukan perhitungan untuk dapat menentukan kesimpulan terhadap penilaian aplikasi yang dibangun.

\section{KESIMPULAN}

Dari hasil perancangan, pengimplementasian, dan pengujian seluruh sistem dalam penelitian ini, maka dapat diambil kesimpulan, sebuah Raspberry Pi 3 berhasil menjalankan sistem pengelola informasi untuk menampilkan video, gambar dan teks berjalan walaupun terdapat beberapa delay pada saat memutarkan video dikarenakan kemampuan raspberry pi 3. Raspberry pi 3 juga berhasil menjadi melakukan komunikasi data dengan PC/Laptop sebagai web manajemen servis untuk melakukan unggahan melalui browser. Dari hasil pengujian kuisioner juga menunjukkan bahwa pengguna aplikasi puas terhadap aplikasi dalam menampilkan informasi berupa konten video, gambar dan teks.

\section{DAFTAR PUSTAKA}

[1] R. T. Perkasa, "Perancangan Pembuatan PerangkatLunakDigital Signage," vol. 2, no. 2, p. 1, 2013.

[2] "Signage Indonesia," 2016. [Online]. Available: http://www.signageindonesia.com/index.php/produk/digitalsignage. 